\title{
STATISTICAL STUDIES ON THE EXCEPTIONAL MUSCLES OF THE KYUSHU-JAPANESE
}

\section{PART 2: THE MUSCLES OF THE NECK}

\author{
SADATO SATO \\ The First Department of Anatomy, Kurume University School of Medicine, \\ Kurume, Japan
}

(Received for publication July 26, 1968)

\section{INTRODUCTION}

The muscles of the neck are an ethnoanatomically interesting group of muscles.

Having, indeed, various morphologically exceptional muscles, this group of muscles seem to raise an anatomically interesting problem, and at the same time it also seems to play an important role as the subject of operation in the fields of otorhinolaryngology and dental surgery.

Therefore, there is a quite large literature on the muscles of the neck, above all the researches concerning the digastricus originating ontogenetically from two embryonal rudiments are too numerous to mention.

In western countries, for instance, there are many morphological and comparative anatomical reports of Eisler (1900), Stracker (1908), Kurz (1918-1919), Steffens and Koerner (1910), E. Loth (1912), Stein(1914-1915), Stevenson (1922), Pangger (1923), Steinbach (1923), Lotoschnikow (1929-1930), Dsatsch (1930) and others, while in our country there are abundant descriptions about the Japanese by Koganei, Arai, Shikinami (1907), Adachi (1910), Nakano (1923), Miyake (1925), Hirako (1930), Mori (1932), Maruyama (1937), Yamada, S. (1934-1935), Tsuda (1940), Fukuyama, Ri, (1941), Morita (1943), Tojima (1950), Shima, Onda, Ichikawa (1956), Fujita (1956), Koura (1960), Yamada, H. (1960) and others.

However, the reports describing the frequency of the exceptional muscles of the neck on the basis of statistic observations of their shapes alone are confined to some parts of them. To our knowledge, there exists no complete description of all the muscles of the neck.

This time at our institute, a statistical observation was made on the frequency of appearance and lack of the muscles of the neck in the Kyushu-Japanese (Platysma, Sternocleidomastoid, Digastric, Sternohyoid, Sternothyroid and Levator of the thyroid gland) as well as on the presence or absence of the tendinous intersection and its number.

The results obtained will be here reported. 


\section{MATERIAL AND METHOD}

The material, the method of observation, and its statistical procedure are exactly as described in Part 1.

\section{OBSERVATIONS}

1) Platysma-

The Platysma represents a thin quadrilateral cutaneous muscle arising from the line connecting the acromion with the anterior end of the 2 nd ( $3 \mathrm{rd}$ ) rib, which reaches the lower part of the face running in- and upward across the margin of the mandible. When it developes best, it reaches even the zygomatic arch or the lower eyelid.

The frequency of appearance of this muscle and the degree of its growth are as follow :

a) The frequency of appearance

As shown in table 1 , this muscle appears in 100 per cent in males of the

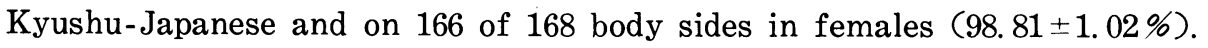

On two body sides of females the Platysma was observed merely as a rudimentary musclar line.

TABLE 1

Frequency appearance of the Platysma

\begin{tabular}{|c|c|c|c|c|c|c|c|c|c|c|}
\hline Side & \multicolumn{3}{|c|}{ Right } & \multicolumn{3}{|r|}{ Left } & \multirow{2}{*}{ D. $\pm \mathrm{m}$. diff. } & \multicolumn{3}{|c|}{ Right + Left } \\
\hline Sex & $\mathrm{T}$ & $\mathrm{n}$ & $\%$ & $\mathrm{~T}$ & $\mathrm{n}$ & $\%$ & & $\mathrm{~T}$ & $\mathrm{n}$ & $\%$ \\
\hline Male & 203 & 203 & $100.00 \pm 0$ & 203 & 203 & $100.00 \pm 0$ & $0 \pm 0$ & 406 & 406 & $100.00 \pm 0$ \\
\hline Female & 134 & 134 & $100.00 \pm 0$ & 134 & 132 & $98.51 \pm 1.05$ & $1.49 \pm 1.21$ & 168 & 166 & $98.81 \pm 1.02$ \\
\hline
\end{tabular}

The comparison of its individual frequency of appearance disclosed no definite difference between the right and the left body sides, and from the sexual point of view, as shown in table 2 , there is no definite difference between both sexes on both body sides, though there exist 2 cases of its lack on the left side of females.

TABLE 2

Sexual difference of the Platysma

\begin{tabular}{c|c|c|c|c|c|c|c}
\hline \multirow{2}{*}{ Sex } & \multicolumn{3}{|c|}{ Male } & \multicolumn{3}{c|}{ Female } & D. \pm m. diff. \\
\cline { 2 - 8 } Side & $\mathrm{T}$ & $\mathrm{n}$ & $\%$ & $\mathrm{~T}$ & $\mathrm{n}$ & $\%$ & \\
\hline Right & 203 & 203 & $100.00 \pm 0$ & 134 & 134 & $100.00 \pm 0$ & $0 \pm 0$ \\
Left & 203 & 203 & $100.00 \pm 0$ & 134 & 132 & $98.51 \pm 1.05$ & $1.49 \pm 1.21$ \\
\hline
\end{tabular}


b) The degree of growth

The Platysma is generally a thin muscle, forming in its upper part a complete sheet of muscle plate composed of laminar muscle bundles adhering closely to each other, but it usually becomes thinner as it goes downward.

The well-developed muscle is relatively thick throughout the whole length of it and forms a muscle plate.

The observation on the degree of growth of these muscle fibers which was divided into 3 grades of,$+ H$, and $H$ for convenience revealed that in the male Kyushu-Japanese $\#$ is most frequent (47.29\%), next + and $H$ in descending order as given in table 3 ; in the female, on the other hand, + is most frequent $(68.66 \%)$, next $H$ and $H$.

TABLE 3

The degree of growth of the Platysma

\begin{tabular}{|c|c|c|c|c|c|c|c|}
\hline \multirow[t]{2}{*}{ Sex } & \multicolumn{3}{|c|}{ Male } & \multicolumn{3}{|c|}{ Female } & \multirow{2}{*}{ D. \pm m. diff. } \\
\hline & $\mathrm{T}$ & $\mathrm{n}$ & $\%$ & $\mathrm{~T}$ & $\mathrm{n}$ & $\%$ & \\
\hline+ & 203 & 75 & $36.95 \pm 3.39$ & 134 & 92 & $68.66 \pm 4.01$ & $\cdot-31.71 \pm 5.25$ \\
\hline$H$ & 203 & 96 & $47.29 \pm 3.50$ & 134 & 38 & $28.36 \pm 3.89$ & - $\quad 18.93 \pm 5.23$ \\
\hline H & 203 & 32 & $15.76 \pm 2.56$ & 134 & 4 & $2.98 \pm 1.47$ & - $\quad 12.78 \pm 2.95$ \\
\hline
\end{tabular}

This indicates a vigorous growth of this muscle in the male as compared with the female.

Especially in the female, the highest grade of its growth (HI) was found only in 4 out of 134 cases, Throughout the grades employed, therefore, there exists a significant difference between both sexes, a fact speaking for a more vigorous growth of this muscle in the male.

2) Sternocleidomastoid-

According to the literature cited, the Sternocleidomastoid is a muscle which originates with 2 heads, one is the sternal head arising from the upper margin of the sternal end with a strong tendon, and the other is the clavicular head arising from the sternal end of the clavicle.

It runs backward up forming a strong muscle belly in combination with the two heads and is attached to the mastoid process and the lateral part of the superior nuchal line of the occipital bone.

From old times the anomaly of its origin has been frequently noted and this muscle is called Cleidomastoid or Sternomastoid depending on the site of its origin.

However, a statistical observation on its abnormal insertion forming a band thick in the front and thin in the back has not yet been mentioned in literature.

As seen in table 4, the abnormal insertion of this muscle was found on 12 of 354 body sides $(3.51 \pm 0.98 \%)$ in the male Kyushu-Japanese and on 10 of 216 
TABLE 4

Abnormal insertion of the Sternocleidomastoid

\begin{tabular}{|c|c|c|c|c|c|c|c|c|c|c|}
\hline Side & \multicolumn{3}{|c|}{ Right } & \multicolumn{3}{|c|}{ Left } & \multirow{2}{*}{ D. $\pm \mathrm{m} . \operatorname{diff}$. } & \multicolumn{3}{|c|}{ Right + Left } \\
\hline Sex & $\mathrm{T}$ & $\mathrm{n}$ & $\%$ & $\mathrm{~T}$ & $\mathrm{n}$ & $\%$ & & $\mathrm{~T}$ & $n$ & $\%$ \\
\hline Male & 177 & 7 & $3.95 \pm 1.46$ & 177 & 5 & $2.82 \pm 1.25$ & $1.13 \pm 1.92$ & 354 & 12 & $3.51 \pm 0.98$ \\
\hline Female & 108 & 5 & $4.63 \pm 2.02$ & 108 & 5 & $4.63 \pm 2.02$ & $0 \pm 2.02$ & 216 & 10 & 4. $63 \pm 1.43$ \\
\hline
\end{tabular}

body sides $(4.63 \pm 1.43 \%)$ in the female.

These anomalies, though small in number as compared with those of its origin, were confirmed in both sexes.

Viewed in dividually, they are found in the male more of ten on the right side than on the left, but there is no definite difference between both sides.

Judging from the sexual point of view, the female tends to show a higher rate of abnormal insertion on both body sides, but there is no definite difference to speak of between two sexes.

TABLE 5

Sexual difference of the Sternocleidomastoid

\begin{tabular}{c|c|c|c|c|c|c|c}
\hline & Sex & \multicolumn{4}{|c|}{ Male } & \multicolumn{3}{c|}{ Female } & D. \pm m. diff. \\
\cline { 2 - 7 } Side & $\mathrm{T}$ & $\mathrm{n}$ & $\%$ & $\mathrm{~T}$ & $\mathrm{n}$ & $\%$ & \\
\hline Right & 177 & 7 & $3.95 \pm 1.46$ & 108 & 5 & $4.63 \pm 2.02$ & $-0.68 \pm 2.49$ \\
Left & 177 & 5 & $2.82 \pm 1.25$ & 108 & 5 & $4.63 \pm 2.02$ & $-1.82 \pm 2.37$ \\
\hline
\end{tabular}

\section{3) Digastric-}

The Digastric consists of 2 muscle bellies, the anterior and the posterior.

The latter arising from the mastoid notch runs forward down hidden by the Sternocleidomastoid and finally shifts into the intermediate tendon.

The former following this runs for-and inward and is attached to the digastric fossa of the maxilla. The intermediate tendon columnar in shape is fixed by a fibrous loop to the body of the hyoid bone in the vicinity of its lesser horn.

Ontogenetically this muscle has been said to be composed of 2 anlages.

TABLE 6

Frequency of lack in appearance of the Digastric

\begin{tabular}{l|r|c|c|r|r|r|r|r|r|r}
\hline \multicolumn{1}{c|}{ Side } & \multicolumn{3}{|c|}{ Right } & \multicolumn{3}{|c|}{ Left } & D. \pm m. diff. & \multicolumn{2}{c}{ Right + Left } \\
Sex & $\mathrm{T}$ & $\mathrm{n}$ & $\%$ & $\mathrm{~T}$ & $\mathrm{n}$ & $\%$ & & $\mathrm{~T}$ & $\mathrm{n}$ & $\%$ \\
\hline Male & 171 & 3 & $1.75 \pm 1.00$ & 171 & 4 & $2.34 \pm 1.16$ & $-0.59 \pm 1.53$ & 342 & 7 & $2.05 \pm 0.77$ \\
Female & 116 & 1 & $0.86 \pm 0.85$ & 116 & 1 & $0.86 \pm 0.85$ & $0 \pm 0.85$ & 232 & 2 & $0.87 \pm 0.60$ \\
\hline
\end{tabular}


Since it is complicated in structure with respectively different innervations, numerous cases of its anomaly were reported by many investigators, but only a few reports have been made on cases of its perfect lack.

As seen in table 6, the perfect lack of this muscle was demonstrated on 7 of 324 body sides $(2.05 \pm 0.77 \%$ ) in the male Kyushu-Japanese, and on 2 of 232 body sides $(0.87 \pm 0.60 \%)$ in the female, that is, the rate of appearance of this muscle is nearly $100 \%$ in both sexes and its rate of lack is no more than $2 \%$ in the male, and $1 \%$ in the female.

Viewed individually, in the male the rate of lack is higher on the left side than on the right, but there exists on definite difference between both body sides.

On sex distinction table 7 showed that the rate of lack is higher in the male than in the female without presenting any significant difference between both body sides.

TABLE 7

Sexual difference of the Digastric

\begin{tabular}{c|c|c|c|c|c|c|c}
\multicolumn{1}{r|}{ Sex } & \multicolumn{3}{|c|}{ Male } & \multicolumn{3}{c|}{ Female } & D. \pm m. diff. \\
Side & $\mathrm{T}$ & $\mathrm{n}$ & $\%$ & $\mathrm{~T}$ & $\mathrm{n}$ & $\%$ & \\
\hline Right & 171 & 3 & $1.75 \pm 1.00$ & 116 & 1 & $0.86 \pm 0.85$ & $0.89 \pm 1.32$ \\
Left & 171 & 4 & $2.34 \pm 1.16$ & 116 & 1 & $0.86 \pm 0.85$ & $1.48 \pm 1.45$ \\
\hline
\end{tabular}

The comparison of the rate of lack in the Kyushu-Japanese with that reported by predecessors revealed that the anomaly of the Digastric is very frequent ranging from $63.3 \%$ of Zlabek as its highest rate to $33.8 \%$ of Fujita. While all the cases reported hitherto were anomalies of its origin and its insertion, the true lack of this muscle has been described only in one case of a Japanese embryo.

Thus, it can be assumed that the more the number of cases to be examined, the more frequent cases of the perfect lack of this muscle may be encountered, since this material of ours only has already shown a rate of lack of $1-2 \%$.

4) Sternohyoid-

The Sternohyoid is a muscle which arises from the manubrium sterni, the sterno-clavicular articular capsule, the clavicle (or the first rib), and the posterior aspect of the sternal end, running upward in a flat rectangular form, and is attached to the body of the hyoid bone.

Therefore, the frequency of appearance of the tendinous intersection seen often in this muscle, its number, and the state of fusion of the left and the right muscles in the anterior part of the neck were statistically observed.

a) The ferquency of appearance of the tendinous intersection

As shown in table 8, the tendinous intersection of the present muscle appe- 
TABLE 8

Frequency of appearance of the tendinous intersection

\begin{tabular}{|c|c|c|c|c|c|c|c|c|c|c|}
\hline Side & \multicolumn{3}{|c|}{ Right } & \multicolumn{3}{|r|}{ Left } & \multirow{2}{*}{ D. \pm m. diff. } & \multicolumn{3}{|c|}{ Right + Left } \\
\hline Sex & $\mathrm{T}$ & $\mathrm{n}$ & $\%$ & $\mathrm{~T}$ & $\mathrm{n}$ & $\%$ & & $\mathrm{~T}$ & $\mathrm{n}$ & $\%$ \\
\hline Male & 169 & 12 & 7. $10 \pm 1.98$ & 169 & 10 & $5.92 \pm 1.82$ & 1. $18 \pm 2.70$ & 338 & 22 & $6.51 \pm 1.34$ \\
\hline Female & 115 & 14 & $12.17 \pm 3.05$ & 115 & 15 & 13. $04 \pm 3.14$ & $-0.87 \pm 4.38$ & 230 & 29 & $12.61 \pm 2.19$ \\
\hline
\end{tabular}

ars on 22 of 338 body sides (6. $51 \pm 1.34 \%$ ) in the male Kyushu-Japanese, and on 29 of 230 body sides $(12.61 \pm 2.19 \%)$ in the female, and its frequency of appearance amounts to about 10 per cent.

On individual observation, it appears more frequently on the right side in the male, and on the left side in the female, but no definite difference is observable between both body sides.

On sexual distinction as seen in table 9, the appearance of the tendinous intersection seems to be more frequent on both sides in the female than in the male without showing any significant difference between both sexes.

TABLE 9

Sexual difference of the Sternohyoid

\begin{tabular}{c|c|c|c|c|c|c|c}
\multicolumn{1}{c|}{ Sex } & \multicolumn{3}{|c|}{ Male } & \multicolumn{3}{|c|}{ Female } & D. \pm m. diff. \\
\cline { 3 - 7 } Side & $\mathrm{T}$ & $\mathrm{n}$ & $\%$ & $\mathrm{~T}$ & $\mathrm{n}$ & $\%$ & \\
\hline Right & 169 & 12 & $7.10 \pm 1.98$ & 115 & 14 & $12.17 \pm 3.05$ & $-5.07 \pm 3.64$ \\
Left & 169 & 10 & $5.92 \pm 1.82$ & 115 & 15 & $13.04 \pm 3.14$ & $-7.12 \pm 3.63$ \\
\hline
\end{tabular}

By comparing the frequency of the tendinous intersection in the KyushuJapanese with that reported by our predecessors it was found that, while the frequency is $15 \%$ in the whites and $6.6 \%$ in the Negroes, these figures are high in the former and low in the latter as compared with the percentage estimated in the Kyushu-Japanese.

b) The number of the tendinous intersection

A detailed observation of the Sternohyoid with the tendinous intersection was made on 22 body sides of males and on 29 body sides of female. Regarding its number it was stated statistically that, as seen table 10 in the male KyushuJapanese the muscle with one intersection was most frequent and found in 21 of 23 cases $(91.30 \pm 5.83 \%)$ and that with two intersections was found only in 2 cases $(8.70 \pm 5.87 \%)$.

In the female, on the other hand, the muscle with one intersection was found in 19 of 29 cases ( $65.52 \pm 8.82 \%$ ) and accounted for the majority of all the cases and that with 2 intersections was encountered in 10 cases ( $34.48 \pm 8.82$ 
TABLE 10

The number of the tendinous intersection

\begin{tabular}{|c|c|c|c|c|c|c|c|c|c|c|c|}
\hline \multirow{2}{*}{\multicolumn{2}{|c|}{ Side }} & \multicolumn{3}{|c|}{ Right } & \multicolumn{3}{|r|}{ Left } & \multirow{2}{*}{ D. \pm m. diff. } & \multicolumn{3}{|c|}{ Right + Left } \\
\hline & & $\mathrm{T}$ & $\mathrm{n}$ & $\%$ & $\mathrm{~T}$ & $\mathrm{n}$ & $\%$ & & $\mathrm{~T}$ & $\mathrm{n}$ & $\%$ \\
\hline \multirow{2}{*}{ Male } & I & 13 & 12 & $92.31 \pm 7.38$ & 10 & 9 & $90.00 \pm 9.49$ & $2.31 \pm 12.00$ & 23 & 21 & $91.30 \pm 5.87$ \\
\hline & II & 13 & 1 & $7.69 \pm 7.38$ & 10 & 1 & $10.00 \pm 9.49$ & $-2.31 \pm 12.00$ & 23 & 2 & $8.70 \pm 5.87$ \\
\hline \multirow{2}{*}{ Female } & I & 14 & 9 & $64.29 \pm 12.79$ & 15 & 10 & $66.67 \pm 12.18$ & $-2.38 \pm 17.66$ & 29 & 19 & $65.52 \pm 8.82$ \\
\hline & II & 14 & 5 & $35.71 \pm 12.79$ & 15 & 5 & $33.33 \pm 12.18$ & $2.38 \pm 17.66$ & 29 & 10 & $34.48 \pm 8.82$ \\
\hline
\end{tabular}

$\%)$. Thus, it can be said that the muscle with one intersection makes up the chief components and that with 2 intersections is small in number.

On sex distinction, as seen in table 11, the muscle with one intersection prevails much on both sides in the male and that with two intersections in the female, but there is no definite difference between both sexes.

TABLE 11

Sexual difference of the number of the tendinous intersection

\begin{tabular}{|c|c|c|c|c|c|c|c|c|}
\hline \multirow{2}{*}{\multicolumn{2}{|c|}{ Sex }} & \multicolumn{3}{|r|}{ Male } & \multicolumn{3}{|c|}{ Female } & \multirow{2}{*}{ D. $\pm \mathrm{m}$. diff. } \\
\hline & & $\mathrm{T}$ & $\mathrm{n}$ & $\%$ & $\mathrm{~T}$ & $\mathrm{n}$ & $\%$ & \\
\hline \multirow{2}{*}{ Right } & I & 13 & 12 & $92.31 \pm 7.38$ & 14 & 9 & $64.29 \pm 12.79$ & $26.02 \pm 14.76$ \\
\hline & II & 13 & 1 & $7.69 \pm 7.38$ & 14 & 5 & $35.71 \pm 12.79$ & $-26.02 \pm 14.76$ \\
\hline \multirow{2}{*}{ Left } & I & 10 & 9 & $90.00 \pm 9.49$ & 15 & 10 & $66.67 \pm 12.18$ & 23. $33 \pm 15.43$ \\
\hline & II & 10 & 1 & $10.00 \pm 9.49$ & 15 & 5 & $33.33 \pm 12.18$ & $-23.33 \pm 15.43$ \\
\hline
\end{tabular}

c) The fusion of the bilateral Sternohyoids

A statistical observation of the state of fusion of the bilateral Sternohyoids in the anterior part of the neck revealed that, as given in table 12 , in the male Kyushu-Japanese it was confirmed in 23 out of 169 cases $(13.61 \pm 2.64 \%)$ and in the female it was found in 5 out of 115 cases $(4.35 \pm 1.90 \%)$.

On sexual distinction, the male tends more of ten to show the state of fusion than the female, which can be said to be a finding peculiar to the male.

TABLE 12

The fusion of the bilateral Sternohyoids

\begin{tabular}{|c|c|c|c|c|c|c|c|c|c|c|}
\hline \multirow[t]{2}{*}{ Sex } & \multicolumn{3}{|c|}{ Male } & \multicolumn{3}{|c|}{ Female } & \multirow{2}{*}{ D. $\pm \mathrm{m}$. diff. } & \multicolumn{3}{|c|}{ Male + Female } \\
\hline & $\mathrm{T}$ & $\mathrm{n}$ & $\%$ & $\mathrm{~T}$ & $\mathrm{n}$ & $\%$ & & $\mathrm{~T}$ & $\mathrm{n}$ & $\%$ \\
\hline & 169 & 23 & $13.61 \pm 2.64$ & 115 & 5 & $4.35 \pm 1.90$ & $\Delta 9.26 \pm 3.25$ & 284 & 28 & $9.86 \pm 1.77$ \\
\hline
\end{tabular}




\section{5) Sternothyroid-}

The Sternothyroid is a muscle which arises from the posterior surface of the manubrium sterni and the cartilage of the first rib, runs behind the Sternohyoid in- and downward and then across the thyroid gland upward, and is inserted to the oblique line on the lamina of the thyroid cartilage.

Therefore, the frequency of the tendinous intersection seen of ten in this muscle, its number, and the state of fusion of the bilateral Sternothyroids were observed statistically.

a) The frequency of the tendinous intersection

As shown in table 13, the tendinous intersection of this muscle is found on 58 out of 362 body sides $(16.02 \pm 1.93 \%)$ in the male Kyushu-Japanese and on 29 out of 234 body sides in the female. $(12.39 \pm 2.15 \%)$ Its frequency amounts to about 15 per cent.

TABLE 13

Frequency of appearance of the tendinous intersection

\begin{tabular}{|c|c|c|c|c|c|c|c|c|c|c|}
\hline Side & \multicolumn{3}{|c|}{ Right } & \multicolumn{3}{|r|}{ Left } & \multirow{2}{*}{ D. $\pm \mathrm{m} . \operatorname{diff}}$. & \multicolumn{3}{|c|}{ Right + Left } \\
\hline Sex & $\mathrm{T}$ & $\mathrm{n}$ & $\%$ & $\mathrm{~T}$ & $\mathrm{n}$ & $\%$ & & $\mathrm{~T}$ & $\mathrm{n}$ & $\%$ \\
\hline Male & 181 & 30 & $16.57 \pm 2.77$ & 181 & 28 & $15.47 \pm 2.69$ & 1. $10 \pm 3.86$ & 362 & 58 & $16.02 \pm 1.93$ \\
\hline Female & 117 & 14 & $11.97 \pm 3.00$ & 117 & 15 & $12.82 \pm 3.09$ & $-0.85 \pm 4.31$ & 234 & 29 & $12.39 \pm 2.15$ \\
\hline
\end{tabular}

On individual observation it tends to appear more often on the right side in the male and on the left in the female, but there exists no definite difference between both body sides.

On sex distinction, as seen in table 14, the male shows a higher frequency of the tendinous intersection on both body sides than the female, but no definite difference is noted between both sexes.

TABLE 14

Sexual difference of the Sternothyroid

\begin{tabular}{c|c|c|c|c|c|c|c}
\multicolumn{1}{c|}{ Sex } & \multicolumn{3}{|c|}{ Male } & \multicolumn{3}{|c|}{ Female } & D. \pm m. diff. \\
\cline { 2 - 6 } Side & $\mathrm{T}$ & $\mathrm{n}$ & \multicolumn{1}{|c|}{$\%$} & $\mathrm{~T}$ & $\mathrm{n}$ & $\%$ & \\
\hline Right & 181 & 30 & $16.57 \pm 2.77$ & 117 & 14 & $11.97 \pm 3.00$ & $4.60 \pm 4.08$ \\
Left & 181 & 28 & $15.47 \pm 2.69$ & 117 & 15 & $12.82 \pm 3.09$ & $2.65 \pm 4.10$ \\
\hline
\end{tabular}

By comparing its frequency in the Kyushu-Japanese with that reported by our predecessors it was revealed that the frequency in the Kyushu-Japanese is lower than that of 22.2 par cent in the Negroes.

b) The number of the tendinous intersection

The Sternothyroid with the tendinous intersection was observed in detail on 58 body sides of male and on 29 body sides of females and the number of its 
tendinous intersection was estimated statistically.

As seen in table 15, in the male Kyushu-Japanese the muscle with one intersection is the highest in frequency. It is found in 43 out of 58 cases ( $74.14 \pm$ $5.75 \%$ ), next the muscle with 2 intersections in 9 cases $(15.52 \pm 4.75 \%)$ that with 3 intersections in 4 cases $(6.90 \pm 3.33 \%)$, and that with 5 intersections in 2 cases $(3.45 \pm 2.26 \%)$.

TABLE 15

The number of the tendinous intersection

\begin{tabular}{|c|c|c|c|c|c|c|c|c|c|c|c|}
\hline \multirow{2}{*}{\multicolumn{2}{|c|}{$\begin{array}{l}\text { Side } \\
\text { Sex }\end{array}$}} & \multicolumn{3}{|c|}{ Right } & \multicolumn{3}{|r|}{ Left } & \multirow{2}{*}{ D. $\pm \mathrm{m}$. diff. } & \multicolumn{3}{|c|}{ Right + Left } \\
\hline & & $\mathrm{T}$ & $\mathrm{n}$ & $\%$ & $\mathrm{~T}$ & $\mathrm{n}$ & $\%$ & & $\mathrm{~T}$ & $\mathrm{n}$ & $\%$ \\
\hline \multirow{5}{*}{ Male } & I & 30 & 22 & $73.33 \pm 8.07$ & 28 & 21 & $75.00 \pm 8.19$ & $-1.67 \pm 11.49$ & 58 & 43 & $74.14 \pm 5.75$ \\
\hline & II & 30 & 5 & $16.67 \pm 6.80$ & 28 & 4 & $14.29 \pm 6.62$ & $2.38 \pm 9.49$ & 58 & 9 & $15.52 \pm 4.75$ \\
\hline & III & 30 & 2 & $6.67 \pm 4.55$ & 28 & 2 & $7.14 \pm 4.87$ & $-0.47 \pm 6.66$ & 58 & 4 & $6.90 \pm 3.33$ \\
\hline & IV & & & & & & & & & & \\
\hline & $\mathrm{V}$ & 30 & 1 & $3.33 \pm 3.27$ & 28 & 1 & $3.57 \pm 3.51$ & $-0.24 \pm 4.80$ & 58 & 2 & 3. $45 \pm 2.26$ \\
\hline \multirow{5}{*}{ Female } & I & 14 & 12 & $85.71 \pm 9.22$ & 15 & 13 & $86.67 \pm 8.78$ & $-0.96 \pm 12.73$ & 29 & 25 & $86.21 \pm 6.40$ \\
\hline & II & 14 & 2 & $14.29 \pm 9.22$ & 15 & 2 & $13.33 \pm 8.78$ & $0.96 \pm 12.73$ & 29 & 4 & $13.79 \pm 6.40$ \\
\hline & III & & & & & & & & & & \\
\hline & IV & & & & & & & & & & \\
\hline & V & & & & & & & & & & \\
\hline
\end{tabular}

In contrast, in the female the muscle with one intersection is most frequent. It is found in 25 out of 29 cases $(86.21 \pm 6.40 \%)$ and that with 2 intersection is found in 4 cases $(13.79 \pm 6.40 \%)$.

However, no muscles with three or more intersections are observed.

TABLE 16

Sexual difference of the number of the tendinous intersection

\begin{tabular}{|c|c|c|c|c|c|c|c|c|}
\hline \multirow{2}{*}{\multicolumn{2}{|c|}{ Side }} & \multicolumn{3}{|r|}{ Male } & \multicolumn{3}{|c|}{ Female } & \multirow{2}{*}{ D. \pm m. diff. } \\
\hline & & $\mathrm{T}$ & $\mathrm{n}$ & $\%$ & $\mathrm{~T}$ & $\mathrm{n}$ & $\%$ & \\
\hline \multirow{4}{*}{ Right } & I & 30 & 22 & $73.33 \pm 8.07$ & 14 & 12 & $85.71 \pm 9.22$ & $-12.38 \pm 12.24$ \\
\hline & II & 30 & 5 & $16.67 \pm 6.80$ & 14 & 2 & $14.29 \pm 9.22$ & $2.38 \pm 11.45$ \\
\hline & III & 30 & 2 & $6.67 \pm 4.45$ & & & & $6.67 \pm 4.45$ \\
\hline & $\mathrm{V}$ & 30 & 1 & $3.33+3.27$ & & & & $3,33+3,27$ \\
\hline \multirow{6}{*}{ Left } & & & & & & & & \\
\hline & I & 28 & 21 & 75. $00 \pm 8.19$ & 15 & 13 & $86.67 \pm 8.78$ & $-11.67 \pm 12.00$ \\
\hline & II & 28 & 4 & $14.29 \pm 6.62$ & 15 & 2 & $13.33 \pm 8.78$ & $0.96 \pm 11.00$ \\
\hline & III & 28 & 2 & $7.14 \pm 4.87$ & & & & $7.14 \pm 4.87$ \\
\hline & IV & & & & & & & \\
\hline & $\mathrm{V}$ & 28 & 1 & $3.57 \pm 3.51$ & & & & $3.57 \pm 3.51$ \\
\hline
\end{tabular}


Accordingly, in both sexes the muscle with one intersection seems to account for the majority of all the cases, and an individual observation revealed no definite difference between both body sides in both sexes.

On sex distinction, as seen in table 16, the muscle with one intersection is more frequent on both sides in the female, which that with two intersections is so in the male, but no definite difference is noted between both sexes.

c) The fusion of the bilateral Sternothyroids

A statistical observation on the state of fusion of the bilateral Sternothyroids in the anterior part of the neck revealed that, as seen in table 17, in the male Kyushu-Japanese it was demonstrated in 13 out of 181 cases $(7.18 \pm 1.92 \%)$ and in the female it was observed in 6 of 117 cases $(5.13 \pm 2.04 \%)$.

TABLE 17

The fusion of the bilateral Sternothyroids

\begin{tabular}{|c|c|c|c|c|c|c|c|c|c|c|}
\hline \multirow[t]{2}{*}{ Sex } & \multicolumn{3}{|c|}{ Male } & \multicolumn{3}{|c|}{ Female } & \multirow{2}{*}{ D. $\pm \mathrm{m}$. diff. } & \multicolumn{3}{|c|}{ Male + Female } \\
\hline & $\mathrm{T}$ & $\mathrm{n}$ & $\%$ & $\mathrm{~T}$ & $\mathrm{n}$ & $\%$ & & $\mathrm{~T}$ & $\mathrm{n}$ & $\%$ \\
\hline & 181 & 13 & 7. $18 \pm 1.92$ & 117 & 6 & $5.13 \pm 2.04$ & $2.05 \pm 2.79$ & 298 & 19 & $6.38 \pm 1.42$ \\
\hline
\end{tabular}

On sex distinction, the fusion is more frequent in the male than in the female, but there is no significant difference between both sexes.

Judging from its frequency, it seem to be a finding peculiar to the male.

6) Levator glandulae thyreoideae-

The levator glandulae thyreoideae is a muscle which arises from the hyoid bone or the thyroid cartilage, or sometimes from other muscles and, running downward, is attached to the isthmus of the thyroid gland, that is, the pyramidal lobe or the lateral lobe of it.

As regards to the frequency of this muscle it was found that, as given in table 18, in the male Kyushu-Japanese it appears on 90 out of 350 body sides $(25.71 \pm 2.34 \%)$, and in the female on 53 out of 220 body sides $(24.09 \pm 2.88 \%)$. Its frequency amounts to about 25 per cent.

TABLE 18

Frequency appearance of the Levator glandulae thyreoideae

\begin{tabular}{|c|c|c|c|c|c|c|c|c|c|c|}
\hline Side & \multicolumn{3}{|c|}{ Right } & \multicolumn{3}{|r|}{ Left } & \multirow{2}{*}{ D. \pm m. diff. } & \multicolumn{3}{|c|}{ Right + Left } \\
\hline Sex & $\mathrm{T}$ & $\mathrm{n}$ & $\%$ & $\mathrm{~T}$ & $\mathrm{n}$ & $\%$ & & $\mathrm{~T}$ & $\mathrm{n}$ & $\%$ \\
\hline Male & 175 & 43 & $24.57 \pm 3.25$ & 175 & 47 & $26.86 \pm 3.35$ & $-2.29 \pm 4.67$ & 350 & 90 & $25.71 \pm 2.34$ \\
\hline Female & 110 & 27 & $24.55 \pm 4.10$ & 110 & 26 & $23.64 \pm 4.05$ & $0.91 \pm 5.76$ & 220 & 53 & $24.09 \pm 2.88$ \\
\hline
\end{tabular}

On individual observation it is more frequent on the left side in the male and on the right in the female, but no definite difference can be noted between 
both body sides.

On sex distinction, as seen in table 19, it appears on both sides more frequently in the male than in the female, but there is no definite difference between both sexes.

TABLE 19

Sexual difference of the Lavator glandulae thyreoideae

\begin{tabular}{l|c|c|c|c|c|c|c}
\multicolumn{1}{r}{ Sex } & \multicolumn{3}{|c|}{ Male } & \multicolumn{3}{c|}{ Female } & \multirow{2}{*}{ D. \pm m. diff. } \\
Side & $\mathrm{T}$ & $\mathrm{n}$ & $\%$ & $\mathrm{~T}$ & $\mathrm{n}$ & $\%$ & \\
\hline Right & 175 & 43 & $24.57 \pm 3.25$ & 110 & 27 & $24.55 \pm 4.10$ & $0.02 \pm 5.23$ \\
Left & 175 & 47 & $26.86 \pm 3.35$ & 110 & 26 & $23.64 \pm 4.05$ & $3.22 \pm 5.26$ \\
\hline
\end{tabular}

Comparison with other neighboring peoples revealed that, as seen in table 20, the frequency of this muscle in the Kyushu-Japanese is lower than that in the Ainu race and the European, and higher than that in the Japanese estimated by Oseki.

TABLE 20

Comparison with other races of the Levator glandulae thyreoideae

\begin{tabular}{|c|c|c|c|c|c|}
\hline \multirow{2}{*}{\multicolumn{2}{|c|}{ Race }} & \multicolumn{3}{|c|}{ Frequency appearance } & \multirow{2}{*}{ Reporters } \\
\hline & & $\mathrm{T}$ & $\mathrm{n}$ & $\%$ & \\
\hline \multirow{2}{*}{ Kyushu Japanese } & Male & 350 & 90 & $25.71 \pm 2.34$ & \multirow{2}{*}{ Sato, S. } \\
\hline & Female & 220 & 53 & $24.09 \pm 2.88$ & \\
\hline \multirow{2}{*}{ Japanese } & Male & 32 & 15 & $46.88 \pm 8.82$ & \multirow{2}{*}{$\begin{array}{l}\text { Kokanai } \\
\text { Arai } \\
\text { Shikiba }\end{array}$} \\
\hline & Female & 6 & 1 & $16.67 \pm 15.22$ & \\
\hline Japanese & & 180 & 34 & $18.89 \pm 2.92$ & Oseki \\
\hline Japanese & & 145 & 59 & $40.69 \pm 4.08$ & Shigeo \\
\hline Aino & & 5 & 5 & 100.00 & Hirakou \\
\hline European & & 120 & 46 & $38.34 \pm 4.44$ & Streckeisen \\
\hline
\end{tabular}

\section{CONCLUSION}

On the adult cadavers of the Kyushu-Japanese domiciled in Fukuoka Prefecture the frequency of appearance and lack of the muscles of the neck, the presence or absence of the tendinous intersection. Its number and the state of fusion of the bilateral muscles were observed and the following results were obtained :

1) The frequency of the Platysma is $100 \%$ in the male and $98.81 \pm 1.02 \%$ in the female. In the latter a picture of rudimentary muscular fibers as such was observed in 2 cases. As regards to the degree of growth, $\#$ in the male and + in the female are most frequent, which indicates that the development of this 
muscle is better in the male than in the female.

2) The abnormal insertion of the Sternocleidomastoid shows a frequency of $3.51 \pm 0.98 \%$ in the male and of $4.63 \pm 1.43 \%$ in the female.

3) Regarding the perfect lack of the Digastric the male shows a frequency of $2.05 \pm 0.77 \%$ and the female frequency of $0.87 \pm 0.60 \%$.

4) The tendinous intersection of the Sternohyoid shows a frequency of 6.51 $\pm 1.34 \%$ in the male and a frequency of $12.61 \pm 2.19 \%$ in the female, and the muscle with one intersection is most frequent in both sexes.

The fusion of the bilateral Sternohyoids is demonstrated in $13.61 \pm 2.64 \%$ in the male and in $4.35 \pm 1.90 \%$ in the female.

5) The tendinous intersection of the Sternothyroid is found in $16.02 \pm 1.93 \%$ in the male and in $13.39 \pm 2.15 \%$ in the female, and the muscle with one intersection is found to be most frequent in both sexes. In the male 2 cases with 5 intersections were observed.

The fusion of the bilateral Sternothyroids was observed in $7.18 \pm 1.92 \%$ in the male and $5.13 \pm 2.04 \%$ in the female.

6) The Levator glandulae thyreoideae appears in $25.71 \pm 2.34 \%$ in the male and in $24.09 \pm 2.88 \%$ in the female.

7) Except for the degree of growth of the Platysma and the frequency of fusion of the bilateral Sternothyroids and Sternohyoids neither side differences nor sexual differences can be noted in other muscles.

\section{ACKNOWLEDGMENT}

The author expresses his sincere thanks to Prof. Yoshio Takeshige and Assist. Prof. Michio Miyazaki for their helpful discussions and support.

\section{REFERENCES}

1) ADACHI, B. : Beiträge zur Anatomie der Japaner. XII. Die Statistik der Muskelvarietäten. Zschr. Morph. Anthrop., 12, 261, 1910.

2) Dratch, S. : Ein Fall von Variationen des M. digastricus mandibulae. Anat. Anz., 69. 81, 1930.

3 ) Eisler, P. : Der M. levator glandulae thyreoideae und verwandte praelaryngeale Muskelbildung. Anat. Anz, 17, 183, 1900.

4) Fujita, A. : Anatomical studies on the M. suprahyoideus of the Japanese. Bull. Anat. Dept. Tokyo med. coll., 1, 1, 1956.

5 ) Funuyama, U. and Ri, B. : Many muscular anomalies seen in one individual. Acta anat. nippon, 18, 395, 1941.

6 ) Huber, E. : Überreste des Sphincter colli profundus beim Menschen. Anat. Anz., 51, 480, 1918-1919.

7 ) Hirako, G. : Studies on the constitution of the Ainu race. Part 1. J. anthrop. Soc. Nippon, 45, 1, Part 2. J. anthrop. Soc. Nippon, 45, 144, 1930.

8 ) KourA, K. : Anatomical studies on the muscles of the neck in the Japanese. J. oral. Anat., 14, 147, 1960. 
9 ) Koganei, R., Arai, Sh. and Shikinami, J. : Statistics on the muscular anomalies. Tokyo J. med. Scis., 17, 127, 1902.

10) Kurz, E. : Muskeln und Nerven der Hals- und Brust-Schultergegend von Macacus rhesus. Arch. Anat. Physiol. Anat., Abt, 225. 1918.

11) Lotoschnikow, A. K. : Die Besonderheiten der Plastik und Topographie des Halses bei einigen Muskelanomalien. Anat. Anz, 68, 151, 1929-1930.

12) Loth, E. : Anthropologische Beobachtungen am Muskelsystem der Neger. Coor. Bl. Anthrop. Ges. Jhg., 42, 117, 1911.

13) Morita, Sh. : On the Platysma of the Japanese and a few Koreans. Acta anat. Nippon, 21, 755, 1943 .

14) Maruyama, Y. : On the M.digastricus mandibulae of the natives of Formosa, with special reference to its variations. J. Formosan med. Ass., 33, 148, 1934.

15) Mori, M. : Abnormal cases of the Sternohyoid, the Sternothyroid and the Claviculahyoid. Act med. (Fukuoka), 6, 235, 1932.

16) Miyake, H. : Das Platysma der Japaner. Fol. Anat. Jap., 3, 139, 1925.

17) Nakano, T. : Beiträge zur Anatomie der Chinesen. Die Statistik der Muskelvarietäten. Fol. Anat. Jap., 1, 237, 1923.

18) Paugger, J. : Beiträge zur Kenntnis der Halsmuskulatur bei Primaten. Zschr, Morph. Anthrop., 23, 185, 1923.

19) Stevenson, P. H. : On a anomalous digastric muscle in the thigh of a Chinese. Anat. Rec., 23, 281, 1922.

20) Stein, M. : Über einen Fall von vollkommenen Mangel des vorderen Digastricusbauches. Anat. Anz., 47, 345, 1914-1915.

21) Stracker, O.: Die Haüfigkeit interponierter Muskelkorper zwischen den vorderen Bäuchen des M.digastricus. 33, 227, 1908.

22) Shima, H. and Onda, K. : Morphological studies on the Platysma of embryos. Rep. Dept. Anat. Tokyo Dent. coll., 1, 17, 1956.

23) Shima, H. and Ichikawa, K. : Anatomical studies on the M. sternocleidomastoideus of Japanese embryos. Rep. Dept. Anat. Tokyo Dent, Coll., 1, 43, 1956.

24) Steinbach, K. : Über Varietäten der Unterzungenbein- und Brustmuskulatur. Anat, Anz., 56, 488, 1923.

25) Steffens, F. und Koerner, O. : Bemerkungen über das Muskelsystem eines Papua-Neugeborenen. Anat. Anz., 36, 1, 1910.

26) Tojima, T. : The morphological study on the anterior belly of the biventer. Jour. Anat. Iwate, 1, 111, 1950.

27) TsudA, M.: Excessive muscle bundles of the Mm.infrahyoidei and the M. trapezius. Iwate Igk. Z., 3, 186, 1940.

28) Yamada, H., Kuga, H. and Ozumi, K. : Case report of abnormities in M. omohyoideus and M. sternothyreoideus. Jour. Kyushu Dent. Soc., 14, 390, 1960.

29) YamadA, S. : Beobachtungen über den Venter anterior des M. digastricus mandibulae bei japanischen Erwachsenen und Foeten. Acta Anat. Nippon, 8, 303, 1935.

30) YAmAdA, S. : Über einige Variationen der Mm. infrahyoidei und Anomalien des clavicularen Ansatzes des M. trapezius an des japanischen Foeten und Neugeborenen. Acta Anat. Nippon, 7, 337, 1934. 